\title{
Virtual Reality: An Innovative Tool in Destinations' Marketing
}

\author{
Mattia Rainoldi*, Veronika Driescher, Alina Lisnevska, Daria \\ Zvereva, Anna Stavinska, Jennifer Relota, and Roman Egger
}

\begin{abstract}
Virtual reality (VR) is a fast-developing technology with a broad range of use. The tourism industry, more specifically destinations, may benefit from its potential in the near future. By using VR in its marketing strategy, destinations have a substantial influence on the information search process and the decision-making process of potential tourists. Tourists can experience the destination, its atmosphere and possible emotions beforehand. Thus, they can create a more detailed destination image and realistic expectations of their visit. This transfers them into a better position to decide whether or not to visit a destination. This experimental study takes a closer look into a destination's promotional material byanalysing and comparing a self-designed brochure withan existing VR video of the city of Dubrovnik, Croatia. A total of 101 experiments were conducted at Fachhochschule Salzburg and UniparkNonntal. The research shows that VR transforms the information search experience into a faster, more interactive, and more detailed process compared to traditional promotional material. The results can be beneficial for destinations to understand how relevant using VR for tourism promotion is.
\end{abstract}

Keywords:virtual reality, destinationmarketing, VR in tourism, customer buying cycle

\section{Introduction}

Innovations intechnology are revolutionising the business world as well as humanity and modern society (Buhalis \& Law, 2008; Guttentag, 2010). Virtual reality $(\mathrm{VR})$ is one of those emerging innovations in information and communication technologies (ICTs) that has the potential to change people's habits, business practices and strategies (Gabisch \& Gwebu, 2011). The revolutionary power of VR has long been recognised. As early as 1995, Hobson and Williams (1995, p.125) described VR

\footnotetext{
* Mattia Rainoldi is Researcher \& Lecturerl Head FHS eTourism Lab Innovation and Management in Tourism, Salzburg University of Applied Sciences, Salzburg, Austria mattia.rainoldi@fh-salzburg.ac.at
} 
as "potentially one of the most important technological breakthroughs of the late $20^{\text {th }}$ century". VR is defined as "the use of a computer-generated $3 \mathrm{D}$ environment called a virtual environment (VE) - that one can navigate and possibly interact with, resulting in a real-time simulation of one or more of the user's five senses" (Guttentag 2010, p. 638).

VR can be used within numerousfields and for different purposes, such as training, educational purposes, entertainment and media, healthcare, architecture and tourism (Mazuryk \& Gervautz, 1996; Virtual Reality Society, 2016). According to Guttentag (2010), VR may be especially valuable for the tourism industry within the following six areas: planning and management, marketing, entertainment, accessibility, education, and heritage preservation. In the marketing area, emerging applications of VR technology are transforming the ways in which tourism products and services are promoted on the market(Guttentag, 2010; Tussyadiah, Wang, \& Jia, 2017). At the same time, VR is changing the way in which travellers search for inspiration and purchase travel experiences (Buhalis \& Law, 2008; Guttentag, 2010).VR creates opportunities to experience and interact with distant realities (Benckendorff, Sheldon, \&Fesenmaier, 2014) by providing tourists a free preview of the vacation experience before purchasing expensive products or services (Cheong, 1995; Neuhofer et al. 2012; Bruce, 2016).

The use of VR may be especially beneficial for destination marketing. Destinations are seen in the literature as the core of the tourism industry, as they combine all products, experiences and services provided locally to customers (Buhalis, 2000; Neuhofer, Buhalis, \& Ladkin, 2012). Additionally, they are seen to be difficult to market and manage due to the complex relationships between all involved stakeholders (Buhalis, 2000; Neuhofer et al., 2012). Emerging ICTs are often reported asdrivers of innovation and creators of value for destinations (Neuhofer et al., 2012; Pawaskar \& Goel, 2014). The integration of ICTs in the destinations' marketing strategy has become crucial for remaining competitive, attracting a wider audience and satisfying tourists' demands and expectations(Buhalis, 1998; Chiou, Wan, \& Lee, 2008; Fritz, Susperregui, \& Linaza, 2005; Pawaskar \& Goel, 2014).

The adoption and acceptance of VR in destination marketing is still however barely explored (Disztinger, Schlögl, \&Groth, 2017).It is therefore necessary, to develop a deeper understanding for VR and its benefits for destinations from a marketing perspective. Hence, this researchseeks to make a contribution to the existing tourism marketing literature by investigating the influence of VR on tourists' intention to visit a destinationwithin the customer buying cycle. 


\section{Literature Review}

\section{Customer Buying Cycle}

The customer buying cycleis a customer relationship management model that provides a structural approach for understanding the relationship and the points of contact between a provider and a customer when products and services are purchased. The customer buying cycle consists of four phases: a) stimulation phase, b) evaluation phase, c) purchasing phase and d) after sales phase (Blecker, Friedrich, Kaluza, Abdelkafi, \& Kreutler, 2005; Meier \& Stormer, 2009).

In the stimulation phase, also often called problem recognition or contact phase, the initial contact betweena provider and a customer is established and the initial interest is evoked.Within this phase, the customer's need for products or services is stimulated (Blecker et al. 2005; Meier \& Stormer, 2009). From a destination perspective, in this phase it is important to create an emotional connection with potential futuretourists(Tourism Australia, 2013).

In the evaluation phase, the customer aims to identify and collectinformation about products and services. The customer may rely on a wide range of offline and online channels for obtaining information. The collection of information is of central importance as it creates the foundation for the comparison of different offers on which the purchase decision will be based (Blecker et al. 2005; Meier \& Stormer, 2009). This is particularly important when purchasing tourism services or experiences, which vary enormously and can only be consumed as they are delivered (Benckendorff et al., 2014). Thus, in tourism, the provision of valuable and detailed information about the product or service offeredis essential for the customer's decision-making process(Varkaris\& Neuhofer, 2017). For a tourism destination, in this phase it is particularly important to show the benefits and qualities of productsand services, and to demonstrate the valueof the destination against major competitors (Tourism Australia, 2013).

In the purchasing phase, the customer makes an order and pays the product or service. Finally, in the after sales phase the customer uses or consumes the product or service bought (Blecker et al. 2005; Meier \& Stormer, 2009).

As this research aims to investigate the influence of VR on tourists' intention to visit a destination, the exploration of the effects of VR on the customer buying cycle will be limited tothe information search process and the decision-making process that take place within the evaluationphase.

\section{Information Search Process}

By using VR in their marketing strategies, destinations have great influence on the information search process of potential or repeating tourists. Buhalis (1998) argues that by using VR, destinations offer tourists to access accurate and reliable information 
in a fraction of cost, time and effort compared to traditional promotional material. This is because VR reduces elements of uncertainty related with the intangible nature of tourism products(Cheong, 1995; Hyun \& O’Keefe, 2012). In addition, Fritz et al. (2005) indicate that new technologies, and VR in particular, have the potential to make the information search process faster and more interactive. This is becausecompared to traditional promotional materials, VR provides consumers with high media richness, interactivity and telepresence(Suh \& Lee, 2005). High media richness refers to the depth and breadth of information (Steuer, 1992). Interactivity is used to describe the consumers' involvement in the computer-mediated environment(Suh \& Lee, 2005), while Telepresence indicates the sense of "being there"(Sheridan, 1992; Steuer, 1992).

According to Zhao (2003), the technologies that can reach the "there" have two main roles. First, to provide a communication channel that allows the flow of information to and from a remote place.Second, to provide an interface that permits users to send and receive information through that channel. In fact, VR gives the opportunity to explore different places, even if the consumer is far away. Through VR, potential tourists are able to see, hear and even feel how it would be to visit a particular destination, attractions or facilities (Bruce, 2016). Thus, VR technologies allow to enhancing the consumers' learning process (Suh \& Lee, 2005; Zarzuela, Pernas, Calzón, Ortega, \& Rodríguez, 2013).

VR allows destinations to supply customers with extensive information and creates realistic expectations about their future holiday (Cheong, 1995; Williams \& Hobson, 1995; Hyun \& O’Keefe, 2012; Zarzuela, Pernas, Calzón, Ortega, \& Rodríguez, 2013). This demonstrates the value of VR in enhancing the information search process. Overall, as information is the lifeblood of the tourism industry(Poon, 1993), VR seems to represent a valuable instrument, which destinations may adopt to improve service quality and contribute to customers' satisfaction (Buhalis, 1998). Therefore, it is expected that VR positivelyinfluencesthe tourist's information search process.

H1: VR has a positive influence on tourist's information search process within the customer buying cycle.

\section{Decision-Making Process}

Recent studies have demonstrated that VR has a great influence not only on the information search process but also on the decision-making process. The decision making process of tourists is generally very complex as it includes several subdecisions (Smallman \& Moore, 2010). Such sub-decisions range from the choice of a destination to the decision of what to do at the destination(Smallman \& Moore, 2010). Additionally, decision-making in tourism usually needs high involvement because of the high risk, which is perceived by the customers(Sirakaya \& Woodside, 2005). 
Touristsare confronted with high risk due to relatively high costs and the intangible nature of tourism products(Sirakaya \& Woodside, 2005).

Furthermore, decision-making is a rational process, which means that potential tourists review the costs and benefits of their actions before purchasing (Sirakaya \& Woodside, 2005). Govers, Go and Kumar (2007)arguethat VR has such a major influence on the decision-making process, as it provides tangible images of the destination and its facilities. Therefore, VR minimises the risk perceived by tourists and provides a more reliable basis to make a rational decision. In addition, Buhalis (2000), Govers et al. (2007) and Nicoletta and Servidio (2012) mention that based on seen images, tourists can create their own mental constructions about facilities and attributes in the destination - the destination image. This destination image and developed expectations have a crucial impact on the intention and motivation to visit a particular destination.

Furthermore, VR has a great influence on the decision-making process, as it touchesand can create intended emotions. According to Achar, So, Agrawal, \& Duhachek (2016), emotions are very important in the decision-making process. VR triggers emotions by stimulating the users' senses, such as seeing, hearing and feeling. VR further stimulates senses by creating an illusive and immersive experience (Gutiérrez, Vexo, \& Thalmann, 2008),in which users are able to visualiseplaces and landscapes, and experienceactivities that they mayenjoy when visiting the destination (Cheong, 1995). VR offers destinations a unique opportunity to transmit intended emotions to potential tourists in a more effective way compared to traditional promotional material(Osti \& Pechlaner2001; Diemer, Alpers, Peperskorn, Shiban, \& Mühlberger, 2015; Felnhofer et al., 2015).Additionally, according to Cuperus, Laken, van den Hout, \& Engelhard (2016) and Serrano, Baños, \& Botella (2016), VR is more powerful in inducing strong emotions, as it creates a feeling of presencethat is traveling virtually to the shown place. Thus, by influencing and stimulating intended emotions through VR, destinations have a great opportunityto influence the decision-making process of potential tourists and to enhance tourism.

Thus, by using VR as a marketing tool, destinations have the unique chance to position themselves and to attract potential tourists (Cheong, 1995; Chiou et al., 2008; Neuhofer et al., 2012). In fact, VR has the potential to influence the image of a destination and its perception by future tourists (Williams \& Hobson, 1995; Buhalis, 2000; Govers et al.,2007; Hyun \& O’Keefe, 2012; Nicoletta \& Servidio, 2012;Zarzuela et al., 2013). Therefore, it can be suggested that VR has a positive influence on tourist's decision-making process.

H2: VR has a positive influence on tourist's decision-making process within the customer buying cycle. 


\section{Methodology}

To answer the research question and to confirm the hypotheses, an experimental research approach wasadopted. The sample was selected using the total population samplewitha purposive sampling approach. The major criteria for the purposive selection were that the sample has a) never visited the destination before and b)that study participantsbelong to Generation Y. Generation Y, also known as Millennials, were born between 1981 and 1999(Bolton et al., 2013).Despite the criticism that Generation $\mathrm{Y}$ may not be representative of general tourism customers $(\mathrm{Ok}$, Shanklin, \& Back, 2008), for this research Generation Yers, have been identified as a representative group of technology adaptors to investigate VR related information search and decision-making processes.

This is because this generation is highly involved with the Internet and techsavvy, as it is the first generation that has been living its entire life in the digital environment (Bolton et al., 2013; Murray, Toulson, \& Legg, 2011; PrincetonOne, 2016). Moreover, Generation Yers are the tourism customers of the future. As of 2020, Generation Y will represent half of the global workforce and will be the largest group of tourism customers (Elworthy, 2016). Additionally, Generation Y is a very optimistic and social group; they tend to easily get engaged with new cultures, traveling and exploring (PrincetonOne, 2016). Thus, it is important for destinations to investigate their future target group right now in order to prepare and adapt to their demand requirements.

Research participants were selected and divided into two groups - the treatment and control group, with the purpose of making a comparison between the two groups. The control group observedtraditional promotional material in form of a brochure, whereas the treatment group saw a VR video of the selected destination. Hence, the VR video and the brochure were the only materials used within this research. To make sure that the content of both promotional materials is consistent, first the VR video was selected and based on this the brochure was created. Additionally, both groups had the same amount of time ( 2 minutes) to observe the material. Furthermore, a pre and post questionnaire wascompletedbythe study participants. The items for the questionnaire were elaborated based on the literature review. These were measured using a 5-point Likert-like scale, from 'Totally agree - Totally Disagree' and 'Poor - Excellent' anchor statements. This was used to test the influence of promotional materials on the information search and decision-making process, and thus, on the actual intention of tourists to visit the potential destination.

Dubrovnik was selected as a destination to carry out the empirical research. This is because the main tourism destinations in Croatia are in the northern and central part of the country (Ministry of Tourism, 2015). Therefore, from a tourism 
marketing point of view the promotion of the southern areas of the country is crucial. Though Dubrovnik is the third most important tourism hub in Croatia after Split and Zagreb.Dubrovnik accounts for $8.9 \%$ of the total overnights in the country (Ministry of Tourism, 2014). In addition, Dubrovnik'sVR video was of very good quality, not too long and packed with valuable information about the destination.

Data were collected on two research sites within Salzburg, namely Fachhochschule Salzburg and UniparkNonntal. Educational institutions were selected as research sites due to the likelihood of finding participants fitting the target sample. Datawere collected using an online questionnaire tool, thus, the data could be easily exported to an excel-file in order to be coded. The analysis of the primary data was doneusing SPSS. In order to ensure reliability of this study, the research instruments were pretested with a pilot-study.

\section{Findings}

A total of 101 experiments were conducted, of which 50 experiments with the treatment group (VR) and 51 experiments with the control group (brochure). In total, $49.5 \%$ of participants are female, $49.5 \%$ are male while $1 \%$ of the sample did not indicate the gender. The majority of participants are from Austria (49.5\%), Germany (12\%) and Italy (4\%). Concerning the educational background,40.6\% have a high school diploma and 50.5\% a bachelor's degree. Lastly, $72.3 \%$ of the participants are currently students, followed by $18.8 \%$ of part-time employees.

To test whether VR has a positive influence on the tourist's information search process and decision-making process, participants were firstly asked to rank the quality of the promotional material(VR video and brochure) on a 5-level Likert Scale ( $1=$ Poor $-5=$ Excellent). The results show a considerable difference between the two promotion media. The VR video $(\mathrm{M}=3.84$; $\mathrm{SD}=0.766)$ was perceived of being of higher quality than the brochure $(\mathrm{M}=2.76$ stars; $\mathrm{SD}=0.951)$. Based on this, it can be concluded that participants preferredthe VR video as a promotional material compared to the brochure. Furthermore, the lower standard deviation within the treatment group (VR) demonstrates a strong agreement on the perceived high quality of VR as a medium for marketing promotion.

Additionally, it was tested whether the promotional material serves its general purpose of promoting the destination Dubrovnik. Participantswere asked to estimate their willingness to visit Dubrovnik prior to and after having inspected or watched the promotional material. The greatest change was observed in the control group (brochure), where the number of participantswishing to visit the destination increased by $13.7 \%$. In contrast, in the treatment group (VR) the noted increase was of $10.0 \%$. Based on these findings, it could be assumed that the brochure better served its purpose of promoting the destination. 
Furthermore, the relationship between the type of promotional material and the intention to visit Dubrovnik after seeing the promotional materials was tested. It can be presumed that the type of promotional material influences a tourist's desire to visit the city afterwards. By considering the results in detail, it can be stated that a larger number of people intend to visit Dubrovnik after seeing the VR video rather than the brochure. The findings can be generalised to Generation $\mathrm{Y}$, as with a value of 0.019 in Pearson's Chi-Square test,this result is statistically significant. By taking into accountthe results of the Cramer's $V$ test (0.234), it can be concluded that the type of promotional material has a positive but rather weak influence on a tourist's desire to visit Dubrovnik. Hence, it can be argued that VR is a more efficient marketing tool compared to traditional brochures. To support this assumption, the influence of each promotional material on the information search process as well as the decisionmaking process of tourists was investigated in detail.

Table 1display the statistical results for each items used to test the influence of VR on the tourist's information search process. Participants where asked to rank every statement on a 5-level Likert Scale ( $1=$ Totally agree $-5=$ Totally Disagree). To verify the inner consistency of the measurement instrument the Cronbach's Alpha test was conducted. TheCronbach's Alphavalue (0.870) demonstrates a strong internal reliability of this battery of statements. The reliability statistics also confirmed that all the adopted items could be accepted, as the Cronbach's Alpha did not increase when items of this construct were excluded from the analysis. Comparing the mean values for the brochure and VR, it can be assumed that VR has a greater positive influence than the brochure onthe information search process.

The information provided through VR resulted in a stronger stimulation of the subject's senses and offered them higher quality information (VR M =1.90; Brochure $M=3.35$ ). In addition, the results show a considerable difference between VR and the brochure in terms of reducing elements of uncertainty. By comparing the mean values between the two promotional media (VR $M=2.06$; Brochure $M=2.75$ ), it can be stated that VR has a positive effect on the information search process. It is also relevant to mention that after watching the VR video,test subjects in the treatment group (VR) indicated a higher degree of feeling like being at Dubrovnik $(\mathrm{M}=1.82)$ than the control group, which looked at the brochure $(M=3.73)$.An equal variance $t$-test revealed a statistically reliable difference between the mean agreement levels to the test items for people who saw the VR video and the brochure. Therefore, H1 can be accepted and it can be concluded that VR has a positive influence on the tourist's information search process. 
Table 1: Descriptives Information Search Process (1=Totally Agree; 5=Totally Disagree)

\begin{tabular}{lccc}
\hline Information Search Process & $\begin{array}{c}\text { Mean } \\
\text { Brochure }\end{array}$ & $\begin{array}{c}\text { Mean } \\
\text { VR }\end{array}$ & $\begin{array}{c}\text { Sig. } \\
\text { (2-tailed) }\end{array}$ \\
\hline $\begin{array}{l}\text { The promotional material provided me with } \\
\text { reliable information in a fast and convenient way. }\end{array}$ & 2.45 & 1.78 & 0.000 \\
\hline $\begin{array}{l}\text { The promotional material reduced elements } \\
\text { of uncertainty by providing me with plentiful } \\
\text { information. }\end{array}$ & 2.75 & 2.06 & 0.000 \\
$\begin{array}{l}\text { The promotional material provided me with high } \\
\text { quality of information and stimulated multiple } \\
\text { senses. }\end{array}$ & 3.35 & 1.90 & 0.000 \\
\hline $\begin{array}{l}\text { The information was presented with high } \\
\text { interactivity. }\end{array}$ & 3.92 & 2.28 & 0.000 \\
\hline $\begin{array}{l}\text { When receiving the information, for a moment I } \\
\text { felt like being in Dubrovnik. }\end{array}$ & 3.73 & 1.82 & 0.000 \\
\hline $\begin{array}{l}\text { With the provided promotional material, learning } \\
\text { about Dubrovnik was enhanced. }\end{array}$ & 2.55 & 1.84 & 0.000 \\
\hline
\end{tabular}

VR also played an important role in the decision-making process. Table 2shows the participants' mean agreement level with the statements used to test the influence of VR on the decision-makingprocess. These were ranked on a 5-level Likert Scale ( $1=$ Totally agree $-5=$ Totally Disagree). The Cronbach's Alphavalue (0.898)obtained by testing the survey items demonstrates high internal consistency and reliability. The results reveal that VR $(M=1.88)$ allows to pre-experience facilities and attractions in a stronger way than the brochure $(\mathrm{M}=2.71)$. In addition, the view ofthe promotional materialresulted in a higher level of confidence about future visitintentions to Dubrovnik among subjectsin the treatment group $(\mathrm{M}=1.80)$ than in the control group, where lower resultswere recorded $(M=2.53)$. However, in terms of creating a clearer destination image, subjects' results show similar valuesbetweenthe VR video $(\mathrm{M}=2.14)$ and the brochure $(\mathrm{M}=2.75)$. An equal variance $t$-test reveals a statistically reliable difference between the two test groups within the decision-making process. These results support $H 2$. Overall, it can be concluded that VR has a positive influence on the tourist's decision-making process. 
Table 2: Descriptives Decision-Making Process (1=Totally Agree; 5=Totally Disagree)

\begin{tabular}{|c|c|c|c|}
\hline Decision-Making Process & $\begin{array}{l}\text { Mean } \\
\text { Brochure }\end{array}$ & $\begin{array}{c}\text { Mean } \\
\text { VR }\end{array}$ & $\begin{array}{l}\text { Sig. } \\
\text { (2-tailed) }\end{array}$ \\
\hline $\begin{array}{l}\text { While seeing the promotional material, I } \\
\text { experienced the atmosphere of Dubrovnik. }\end{array}$ & 2.71 & 1.88 & $0.007^{\star}$ \\
\hline $\begin{array}{l}\text { While seeing the promotional material, I was } \\
\text { able to pre-experience facilities and attractions in } \\
\text { Dubrovnik. }\end{array}$ & 3.14 & 1.98 & $0.001^{*}$ \\
\hline $\begin{array}{l}\text { After seeing the promotional material, I am in a } \\
\text { better position to decide whether I want to travel } \\
\text { or not to Dubrovnik. }\end{array}$ & 2.53 & 1.80 & 0.000 \\
\hline $\begin{array}{l}\text { After seeing the promotional material, I have } \\
\text { realistic expectations of a future visit in my head. }\end{array}$ & 2.71 & 2.08 & 0.001 \\
\hline $\begin{array}{l}\text { After seeing the promotional material, my desire } \\
\text { to visit Dubrovnik is stronger. }\end{array}$ & 2.71 & 2.02 & 0.001 \\
\hline $\begin{array}{l}\text { After seeing the promotional material, I have a } \\
\text { clear destination image in my head. }\end{array}$ & 2.75 & 2.14 & 0.002 \\
\hline $\begin{array}{l}\text { The promotional material touched on and } \\
\text { induced emotions. }\end{array}$ & 3.35 & 1.98 & 0.000 \\
\hline
\end{tabular}

* Significance level based on Levene's Test for Equality of Variances

\section{Discussion}

The study's aim was to investigate a destination's promotional material by analysing and comparing a self-designed brochure with an existing VR video of the city of Dubrovnik, Croatia. The first objective was to investigate the influence of VR on the tourist's information search process within the customer buying cycle. The results of this research can to a large extent confirm the previous scientific findings. Referring back to the statements of Buhalis (1998) and Fritz et al. (2005), VR guarantees a faster and more interactive information search process. Thus, according to the perceptions of the participants of this research framework, VR provided them with a more reliable and interactive information search process in a fast way, compared to the traditional promotional materials, such as brochures.

The research findings confirm the statements by Cheong (1995) and Hyun \& O'Keefe (2012) that VR reduces elements of uncertainty and the intangible nature of tourism 
products in a better way, as it supplies tourists with plentiful information, compared to traditional promotional material. Additionally, due to the abundanceof information, tourists are able to create more realistic expectations compared to a brochure.

Furthermore, the results confirm the study of Suh \& Lee (2005)arguing that VR provides consumers with high media richness, interactivity and telepresence. The results have revealed that the quality of the provided information was higher than in the case of the brochure. Additionally, it has been demonstrated that multiple senses, such as vision and hearing are stimulated since the information is presented in an interactive way.

Comparing the findings of Suh \& Lee (2005)to the results of this study, it can also be affirmed that the learning process was stimulated. The VR video permitted to see realistic images of Dubrovnik from different angles and distances. Furthermore, the participants could adjust from which angle to explore the destination, which permitted a higher level of interactivity that in turn enhanced the customer learning process, in line withSuh \& Lee (2005) and Zarzuela et al. (2013). Furthermore, the VR video strongly affected the sense of "being there" (telepresence) as soon as the participants stated that for a moment they felt like being in Dubrovnik.

It is interesting to point out that the video contains realistic images of the place, such as for example, the rain that is normally avoided in traditional promotional materials. The participants of the treatment group were having fun seeing how the rain drops were flying into them, some participants of the control group found that the rain was not very positive for the destination image.

The second objective of this study was to analyse the influence of VR on the customer decision-making process. The findings have revealed that VR does have a positive influence. The VR video provided the participants with better information and allowed pre-experiencing the destination. Consequently, participants could explore and experience the destination facilities, weather and atmosphere in more depth, as proposed by Bruce (2016), Cheong (1995) and Chiou et al. (2008). Hence, the research findings confirm the statements of Williams and Hobson (1995) and Zarzuela et al. (2013) that tourists - after seeing VR as a promotional material - are in a better position to makea decision about whether or not to visita destination. This is because tourists can build more realistic expectations based on a VR video than when looking at a brochure.

The findings of this study also confirm the statements of Cheong (1995)that VR increases the actual desire to visit the place. Thus, the participants expressed not only a higher desire to visit Dubrovnik, but also argued to have a clearer perception of the place, hence, a high-quality destination image. It could lead to a more rational decision from the customer's side and minimise the risk related to high expectations. 
Finally, VR has shown to evoke more emotions in the customer's mind. Thus, the participants were not only watching or listening to the video, but they were also moving or sometimes jumping (e.g. to avoid the rain) what can also confirm that they were more immersed and involved in the experience. Additionally, the results confirm that the treatment group was more emotionally touched what could affirm the stimulation of the senses.

\section{Conclusion}

The findings suggest some useful implications for destination practice. First, the use of VR could provide future tourists with more reliable, faster, and more interactive information and, in this way, influence the tourist's information search and decision-making process. This kind of information permits to pre-experience the destination and create realistic expectations about the place. Subjects had a more detailed destination image as well as realistic expectations of the possible visit. All this together placed them into a better position to decide whether or not to visita specific destination. Hence, it can be argued thatVR videos can be adopted as a useful and beneficial marketing tool for destinations. It was confirmed that VR enable destinations to attract a wider audience and to satisfy tourists' demands and expectations, and by doing so, to stay competitive in the tourism industry.

VR stimulates multiple senses thanks to the fact that the information is presented in an interactive way, and it creates a feeling of presence. This information is critical for destinations currently looking to creating VR content, as to design videos that address various senses and touch emotionally, while delivering information in a fast and convenient way.

\section{Limitations and Further Research}

Several limitations are acknowledged. Due to the quantitative nature of this study, limitations in time andin sample size need to be considered. Due to the focus of the sample on Generation Y, the results of this study cannot be generalised to a larger population, only to Generation Y. The questionnaire was offered in English language only, which could represent a possible language barrier for study participants and those having to be excluded from the study due to the language of the study.

Additionally, the provided brochure could also represent another limitation as it was producedbased on the information from the video. This study assured to display the same information in the video and in the brochure. However, some elements, such asthe rain, could have been perceived in a different manner. In this sense, it would be appropriate to use a variety of promotional materials in further research, such as, for example, professional brochures, photos or regular promotional videos and compare them with the effect of VR videos. 
Further research should extend the sample size, taking into account other generations, such as Baby Boomers, Generation X and Generation Z. It would also be important to analyse and compare the differences of VR's influence on other parts of the customer buying cycle, such as the stimulation phase, purchasing phase and after sales phase. In addition, future research could aim to investigate whether there is any variation in perceiving content and whether videos with more or less information influence the viewer in the decision-making process.

\section{References}

Achar, C., So, J., Agrawal, N. \& Duhachek, A. (2016). What we feel and why we buy: The influence of emotions on consumer decision-making.Current Opinion in Psychology, 10, 166-170.

Benckendorff, P. J., Sheldon, P. J. \& Fesenmaier, D. R. (2014). Tourism information technology. Wallingford: Cabi.

Blecker, T., Friedrich, G., Kaluza, B., Abdelkafi, N. \& Kreutler, G. (2005). Information and management systems for product customization. New York: Springer.

Bolton, R. N., Parasuraman, A., Hoefnagels, A., Migchels, N., Kabadayi, S., Gruber, T., ... Solnet, D. (2013). Understanding generation Y and their use of social media: A review and research agenda. Journal of Service Management, 24(3), 245-267.

Bruce, S. (2016). How to use virtual reality for public relations. Retrieved May 11, 2016, from http://influence.cipr.co.uk/2016/02/11/use-virtual-reality-publicrelations/

Buhalis, D. (1998). Strategic use of information technologies in the tourism industry. Tourism Management, 19(5), 409-421.

Buhalis, D. (2000). Marketing the competitive destination of the future. Tourism Management, 21(1), 97-116.

Buhalis, D., \& Law, R. (2008). Progress in information technology and tourism management: 20 years on and 10 years after the internet: The state of eTourism research. Tourism Management, 29(4), 609-623.

Cheong, R. (1995). The virtal threat to travel and tourism. Tourism Management, $16(6), 417-422$.

Chiou, W. B., Wan, C. S. \& Lee, H. Y. (2008). Virtual experience vs. brochures in the advertisement of scenic spots: How cognitive preferences and order effects influence advertising effects on consumers. Tourism Management, 29(1), 146-150.

Cuperus, A. A., Laken, M., van den Hout, M. A. \& Engelhard, I. M. (2016). Degrading emotional memories induced by a virtual reality paradigm. Journal of Behavior Therapy and Experimental Psychiatry, 52, 45-50. 
Diemer, J., Alpers, G. W., Peperskorn, H. M., Shiban, Y. \& Mühlberger, A. (2015). The impact of perception and presence on emotional reactions: A review of research in virtual reality. Frontiers in Psychology, 6(26).

Disztinger, P., Schlögl, S. \& Groth, A. (2017). Technology acceptance of virtual reality for travel planning. In R. Schegg, \& B. Stangl (Eds.),Information and Communication Technologies in Tourism 2017. Cham: Springer, 255-268.

Elworthy, S. (2016). Why the future is up to generation Y. Retrieved November 16, 2016, from http://www.tea-after-twelve.com/all-issues/issue-03/issue-03overview/chapter2/generation-y/

Felnhofer, A., Kothgassner, O. D., Schmidt, M., Heinzle, A. K., Beutl, L., Hlavacs, H. \& Kryspin-Exner, I. (2015). Is virtual reality emotionally arousing? Investigating five emotion inducing virtual park scenarios.International Journal of Human Computer Studies, 82, 48-56.

Fritz, F., Susperregui, A. \& Linaza, M. (2005). Enhancing cultural tourism experiences with augmented reality technologies. In The 6th International Symposium on Virtual Reality Archaeology and Cultural Heritage (VAST). 6th International Symposium on Virtual Reality, Archaeology and Cultural Heritage (VAST), 1-6. Retrieved from http://public-repository.epoch-net. org/publications/VAST2005/shortpapers/short2005.pdf

Gabisch, J. A. \& Gwebu, K. L. (2011). Impact of virtual brand experience on purchase intentions: The role of multichannel congruence. Journal of Electronic Commerce Research, 12(4), 302-320.

Govers, R., Go, F. M. \& Kumar, K. (2007). Promoting tourism destination image. Journal of Travel Research, 46(1), 15-23.

Gutiérrez, M., Vexo, F., \& Thalmann, D. (2008). Stepping into virtual reality. London: Springer.

Guttentag, D. A. (2010). Virtual reality: Applications and implications for tourism. Tourism Management, 31(5), 637-651.

Hyun, M. Y. \& O’Keefe, R. M. (2012). Virtual destination image: Testing a telepresence model. Journal of Business Research, 65(1), 29-35.

Mazuryk, T. \& Gervautz, M. (1996). Virtual Reality: History, Applications, Technolgy and Future. Wien. Retrieved from https://www.cg.tuwien. ac.at/research/publications/1996/mazuryk-1996-VRH/

Meier, A. \& Stormer, H. (2009). eBusiness \& eCommerce: Managing the digital value chain. Heidelberg: Springer.

Ministry of Tourism. (2014). Tourism in Figures 2014. Zagreb. Retrieved from http://www.mint.hr/UserDocsImages/150701_Tourism014.pdf 
Ministry of Tourism. (2015). Croatian Tourism 2015. Zagreb. Retrieved from http://www.mint.hr/UserDocsImages/Stats_2015_eng.pdf

Murray, K., Toulson, P. \& Legg, S. (2011). Generational cohorts' expectations in the workplace: A study of new zealanders.Asia Pacific Journal of Human Resources, 49(4), 476-493.

Neuhofer, B., Buhalis, D. \& Ladkin, A. (2012). Conceptualising technology enhanced destination experiences.Journal of Destination Marketing and Management, 1, 3646.

Nicoletta, R. \& Servidio, R. (2012). Tourists' opinions and their selection of tourism destination images: An affective and motivational evaluation. Tourism Management Perspectives, 4, 19-27.

Ok, C., Shanklin, C. W. \& Back, K. (2008). Generalizing survey results from student samples: Implications from service recovery research.Journal of Quality Assurance in Hospitality \& Tourism, 8(4), 1-23.

Osti, L. \& Pechlaner, H. (2001). Communication Issues in NTO Distribution Strategies. In D. Buhalis \& E. Laws (Eds.), Tourism Distribution Channels: Practices, Issues and Transformations. London: Thomson Learning, 231-242.

Pawaskar, P. \& Goel, M. (2014). A conceptual model: Multisensory marketing and destination branding.Procedia Economics and Finance, 11(14), 255-267.

Poon, A. (1993). Tourism, technology and competitive strategies. Wallingford: CABI Publishing.

PrincetonOne. (2016). Understanding generation Y: What you need to know about the millennials. Skillman. Retrieved from http://www.princetonone. com/news/PrincetonOne White Paper2.pdf

Sheridan, T. B. (1992). Musings on telepresence and virtual presence. Presence: Teleoperators \& Virtual Environments, 1(1), 120-126.

Serrano, B., Baños, R. M. \& Botella, C. (2016). Virtual reality and stimulation of touch and smell for inducing relaxation: A randomized controlled trial. Computers in Human Behavior, 55, 1-8.

Sirakaya, E. \& Woodside, A. G. (2005). Building and testing theories of decision making by travellers. Tourism Management, 26(6), 815-832.

Smallman, C. \& Moore, K. (2010). Process studies of tourists' decision-making. Annals of Tourism Research, 37(2), 397-422.

Steuer, J. (1992). Defining virtual reality: Dimensions determining telepresence. Journal of Communication, 42(4), 73-93. 
Suh, K. \& Lee, Y. (2005). The effects of virtual reality on consumer learning: An empirical investigation. MIS Quarterly, 29(4), 673-697.

Tourism Australia. (2013). Distribution 2020: Situational analysis. Retrieved from http://www.tourism.australia.com/documents/corporate/Distribution_Final_ Fullreport.pdf

Tussyadiah, I. P., Wang, D. \& Jia, C. H. (2017). Virtual reality and attitudes toward tourism destinations. In R. Schegg, \& B. Stangl (Eds.), Information and Communication Technologies in Tourism 2017. Cham: Springer, 229-239.

Varkaris, E., Varkaris, E., Neuhofer, B. \& Neuhofer, B. (2017). The influence of social media on the consumers' hotel decision journey. Journal of Hospitality and Tourism Technology, 8(1), 101-118.

Virtual Reality Society. (2016). Applications of virtual reality. Retrieved June 24, 2016, from http://www.vrs.org.uk/virtual-reality-applications/

Williams, P. \& Hobson, J. P. (1995). Virtual reality and tourism: fact or fantasy? Tourism Management, 16(6), 423-427.

Zarzuela, M. M., Pernas, F. J. D., Calzón, S. M., Ortega, D. G. \& Rodríguez, M. A. (2013). Educational Tourism through a Virtual Reality Platform. Procedia Computer Science, 25, 382-388.

Zhao, S. (2003). "Being there" and the role of presence technology. In G. Riva, F. Davide \& W. Ijsselsteijn (Eds.), Being There: Concepts, effects and measurement of user presence in synthetic environments. Amsterdam: Ios Press, 138-146. 